\title{
Country size and public good provision
}

\author{
Klaas Staal* \\ February 17, 2004
}

\begin{abstract}
This paper studies the equilibrium size of countries. Individuals in small countries have greater influence over the nature of political decision making while individuals in large countries have the advantage of more public goods and lower tax rates. The model implies that (i) there exists excessive incentives to separate, though this need not be the case for all sets of secession rules studied; (ii) an exogenous increase in public spending decreases country size; (iii) countries with a presidential-congressional democracy are larger than countries with a parliamentary democracy.
\end{abstract}

Key Words: country size, public spending, structure of government.

JEL Numbers: D7, H1, H2, H7.

\footnotetext{
*Tinbergen Institute, Erasmus University, PO 1738, 3000 DR Rotterdam, the Netherlands. E-mail: staal@few.eur.nl

I would like to thank Dennis Fok, Sanjeev Goyal, Henk Hoogland, Jo Thori Lind and Maaike van den Berg and participants at presentations in the Erasmus University (Rotterdam), the University of Essex (Colchester) and the Centrum for European Integration Studies (Bonn) for helpful suggestions.
} 


\section{Introduction}

Political instability and border redrawings are quite common. A few examples are former republics like the Soviet Union, Yugoslavia and Czechoslovakia or the Basques in Spain and the Kurds in Iraq and surroundings. The number of countries has increased significantly in the last century, from 62 in 1914 to 193 at present. ${ }^{1}$ This increase is induced partly by decolonization, but also in for example Europe the number of countries increased, from 32 to 48. Another development is the significant increase in public spending, as a share of GDP as well as in absolute terms: public spending rose from 10,7\% around 1870, 27,9\% in 1960 to $45,6 \%$ in 1996 for a group of 17 industrial countries. These figures include redistribution but also government real expenditure, defined as the sum of government salaries and supplies purchased by the government, increased from $4,6 \%$ around $1870,12,6 \%$ in 1960 to $17,3 \%$ in $1995 .^{2}$

Border changes and the equilibrium number of countries are studied by Alesina and Spolaore (1997) and this paper extends their seminal work. In their research, country formation is the result of a specific trade-off between the benefits of larger political entities and the costs of heterogeneity in larger communities. The benefit of living in larger countries is that the fixed costs of having a government can be spread over more individuals. The increase in public spending mentioned above therefore increases the incentives to form larger countries, which contradicts the increase in countries observed in the same period. Since the benefits of having a government are not fixed in the model of this paper, as they are in Alesina and Spolaore's research, the increase in public spending does not lead to a conclusion which contradicts the increase in the number of countries mentioned above.

One of the core assumptions of the Alesina and Spolaore (1997) model is thus that the benefits and the costs of public goods are assumed to be fixed, i.e. do not depend on country size. Alesina and Wacziarg (1998), however, present empirical evidence that total public spending is increasing in country size. Although the results of Alesina and Spolaore generalize when public spending increases linearly with country size, the benefits of public spending remain constant. This leads to the anomaly that the benefits of a good are not increasing in the amount of the

\footnotetext{
${ }^{1}$ See The Economist, January 3, 1998, pp.63-65.

${ }^{2}$ The data on public spending come from Tanzi and Schuknecht (2000), Table I.1 and Table II.1.
} 
good nor in the resources used to provide these goods. Another implication of the fixed benefits and fixed costs assumptions is that if the increase in public spending mentioned above is modelled as an increase in fixed costs, the equilibrium size of countries will increase. This contradicts the increase in the number of countries mentioned at the start of the introduction. In my analysis I therefore assume that total public spending as well as the payoff from public spending is increasing in country size.

The payoff of the public good is increasing in country size since larger countries spend more on public goods. Apart from this, there are other reasons why the payoff from the government is higher in larger countries. Two reasons are given by Alesina and Spolaore themselves. Firstly, larger countries are less susceptible to uninsurable shocks. Secondly, security considerations are smaller in larger countries. One more reason is given by Le Breton and Weber (2001). In some countries, particularly China, France, Russia, India and Pakistan citizens value their country's political and military might. Since a country's standing and influence in the world is increasing in its size, the payoff from government (public good) is increasing in country size.

Alesina and Wacziarg (1998) present empirical evidence that public spending is increasing less than proportionally in country size. In my model the per capita costs of government is therefore decreasing in country size and the payoff of government is increasing in country size. I use unidimensional spatial modelling of the heterogeneity of citizen's preferences among voters over the provision of public goods. In the next part of the analysis I still use spatial modelling and the payoff of government is still increasing in country size, but solely on account of the larger public spending by larger countries. This makes it possible to study two more topics which cannot be studied using fixed costs and fixed benefits assumptions. Firstly, I examine the effect of the previously mentioned massive increase in public spending on the equilibrium size of countries. Secondly, I investigate how institutions for public good provision, i.e. how presidential-congressional regimes and parliamentary regimes, affect country size.

The main results in this paper are the following. Equilibrium country size depends on the balance between on the one hand the diminishing marginal returns of country size and on the other hand the increasing political costs. Under more general assumptions than in the existing literature, I find that the equilibrium size 
of countries is smaller than socially optimal under certain rules for secession, while for other rules it is not. An increase in public spending decreases the equilibrium and the socially optimal size of countries. Finally, I argue that the equilibrium size of countries with parliamentary regimes is smaller than the equilibrium size of countries with presidential-congressional regimes. I discuss these results in more detail below.

In models with a fixed costs and fixed benefits assumption for public spending it is a general finding that majority voting leads to excessive incentives for separation from a social point of view. In my model, however, there is an additional advantage of an increase in country size since the payoff from government also increases. The aggregate marginal benefits of increasing country size are equal to an individual's marginal benefits. But the costs of losing political influence for an individual are still larger than the aggregate costs when country size increases. This implies that there are still excessive incentives for separation. When the possibility of secession is however limited, like it often is in practice, equilibrium country size need not be smaller than the socially optimal country size.

Intuitively, an exogenous increase in public spending can have two opposite effects. On the one hand, more public spending and thus a higher payoff from public spending makes it more important for individuals to locate the public good nearby, inducing a smaller equilibrium size of countries. On the other hand, an increase in public spending makes it more important to share the costs over a larger number of individuals, thus inducing a greater equilibrium size of countries. Beforehand, it is not obvious which effect will prevail. I show that an exogenous increase in public spending has a negative effect on equilibrium country size. This effect is created by on the one hand the diminishing marginal benefits of public spending and on the other hand the increase in the importance of the transportation costs. More public spending implies that the marginal benefits are lower, which means that the decrease in total public spending when country size decreases becomes less important. Moreover, more public spending also implies that it becomes more important to have a type of public good relatively similar to the most preferred type, which is more likely to happen in smaller countries. ${ }^{3}$

\footnotetext{
${ }^{3}$ One may argue that the relative importance of public spending has increased due to a decrease in the average size of a country. There are, however, external factors explaining the increase in public spending, for example by the increase in economic openness. Rodrik (1998) argues that openness induces a larger susceptibility to external shocks and that open countries
} 
In a presidential-congressional democracy, there is a clearer separation of legislative and executive power than in a parliamentary democracy. Based on a spatial model I show that the greater separation of the legislative and the executive power in a presidential-congressional democracy implies that public spending is smaller under presidential-congressional regimes. Since I also find that an increase in public spending has a negative influence on country size, this implies that the equilibrium size of countries with parliamentary regimes is smaller than the equilibrium size of countries with presidential-congressional systems. Persson, Roland and Tabellini (2000) give empirical evidence that public spending is smaller under presidential-congressional regimes than under parliamentary regimes.

Before proceeding with the research, I first mention some related literature. For a more extensive discussion of some of the literature see Bolton, Roland and Spolaore (1996).

Hotelling's (1929) location model representing the heterogeneity of voters over the provision of public goods is also used (implicitly or explicitly) by Alesina and Spolaore (1997), Le Breton and Weber (2001), Goyal and Staal (2003), Casella (1992), Casella and Feinstein (1990), Etro (2003), Feinstein (1992) and Wei (1991a,b). The authors of the first three papers assume that the public good has fixed costs and fixed benefits while in this paper the spending on and the payoff of the public good is increasing in country size. In the latter six papers the focus is on political integration and trade. In their papers, Casella and Feinstein specify a functional form for the relationship between taxes and the public good which satisfies the assumptions made in this paper. In these three papers, however, the focus is on market partition and trade, while my focus is more on secession in a political jurisdiction and public spending.

Heterogeneity in income is the primary focus in the papers by Buchanan and Faith (1987), Fidrmuc (1999) and Bolton and Roland (1997). This literature shows that fiscal accommodation does not prevent the break-up of countries under all circumstances and that fiscal accommodation may lead to higher taxes. The

therefore need a larger public sector to provide a stabilizing role. Rodrik (1998) and Alesina and Wacziarg (1998) also present empirical evidence that openness and government spending are positively related. 
focus of this part of the literature is primarily on redistribution confllicts, not on preference heterogeneity over public good provision.

The choice between centralization and decentralization of policy with spillovers across countries or regions is studied by Besley and Coate (1999), Ellingsen (1998) and Lockwood (2002). In contrast with the findings when using spatial modelling, they find that there can be either too little or too much integration in equilibrium. In these papers, centralized policy is nonuniform, while in this paper centralized policy making leads to uniform outcomes.

Individuals can also form a federation. Persson and Tabellini (1996a,b) focus on the the risk sharing in a federation under moral hazard considerations and not on the role of preference diversity over public goods like this paper. Bordignon and Brusco (1999) argue that the absence of explicit secession rules can be seen as a commitment device to increase the stability of the federation.

In the remaining of the paper I start with discussing the model and its assumptions in Section 2. Section 3 studies the socially optimum and the equilibrium outcome and discusses the rules which are used in the model for creating countries. In Section 4 I explore the role of public good provision, the effects of an increase in public spending and the influence of forms of governments on country size. Section 5 concludes and most proofs are in the Appendix.

\section{Model}

Like Alesina and Spolaore (1997) I focus on the trade-off between the benefits of large countries and the accompanying costs of heterogeneity in large populations. They argue that larger political jurisdictions bring about several benefits. Firstly, the per capita costs of several public goods is decreasing with the population size. Secondly, increasing returns in the size of the economy implies increasing returns in the size of countries. Thirdly, exposure to uninsurable shocks is more costly for smaller countries. Lastly, security considerations can be taken more effectively by larger countries. Le Breton and Weber (2001) argue that in addition larger countries have a larger standing in the world, making citizens better off. The counterbalancing effect of increasing the size of political jurisdictions is that individuals are less likely to get the type of public goods they prefer. 
In order to keep the model tractable, I consider only one public good (type of government, public service), which identifies each country. The public good identifies a bundle of administrative, judicial and economic services and other public policies. I consider only a single dimension along which the different possible types of public goods are distributed. This dimension stretches form minus infinity to plus infinity. I assume that there is a world population with ideal points distributed evenly on the same dimension. Individuals' utility is decreasing with the distance of their government from their ideal point. Distance can be interpreted in a geographical and in a preference dimension. In the former interpretation, utility is decreasing since individuals further away from the government have higher transportation costs and in the latter, utility is decreasing since the type of public goods provided differs more from the most preferred type.

Every country needs a single government and the citizens of each country have to finance and can take advantage of the only government of their country. Individuals will first vote on the amount of public goods provided by their government, then they will vote on the type of public goods. I use $s_{i}$ for the size of a country $i$.

The maximum utility of the public good in country $i$ depends on the size of the country and is denoted by $g\left(s_{i}\right)$, satisfying the following assumptions:

$$
(A 1) \quad \begin{cases}g^{\prime}(s) \geq 0 & \forall s \\ g^{\prime \prime}(s) \leq 0 & \forall s \\ \text { Inada: } & \lim _{s \rightarrow 0} g^{\prime}(s)=\infty \\ & \lim _{s \rightarrow \infty} g^{\prime}(s)=0\end{cases}
$$

The assumptions imply that government is a normal good: the maximum payoff of the government is increasing in country size (for the reasons mentioned above), but the marginal increase diminishes for larger country sizes. In addition, I assume that $g(s)$ satisfies Inada-type conditions. These conditions state that the marginal gain in utility of increasing the size of the jurisdiction is arbitrary large when the jurisdiction is sufficiently small and that the marginal gain is very small when the jurisdiction is sufficiently large. The Inada conditions are necessary to insure that there exist equilibrium country sizes and socially optimal country sizes.

The loss in utility when an individual suffers when the type of government is far from his preferred type is measured by the positive parameter $a$. The 
preference distance from individual $i$ to his government is denoted by $d(i)$. Every individual has the same exogenous income $y$.

The lump-sum tax level an individual in country $i$ has to pay also depends on country size and is denoted by $t\left(s_{i}\right)$, which satisfies the following assumptions:

$$
(A 2) \begin{cases}t(s)>0 & \forall s \\ t^{\prime}(s)<0 & \forall s \\ t^{\prime \prime}(s)>0 & \forall s \\ \lim _{s \rightarrow \infty} t^{\prime}(s)=0 & \end{cases}
$$

These conditions state that the tax level is always positive and a convex function of country size. The assumptions are consistent with the findings of Alesina and Wacziarg (1998). The marginal decrease in the tax level is arbitrary small for sufficiently large countries.

The aggregate payoff of the public good in a country is $s g(s)$ which satisfies the following assumptions:

$$
\left\{\begin{array}{l}
\left(\frac{d}{d s}\right)^{2} s g(s)>0 \\
\lim _{s \rightarrow \infty} \frac{d}{d s} s g(s)=g(s)
\end{array} \forall s\right.
$$

The aggregate payoff of the public good in a country is increasing faster in the size of the country for larger countries since public good provision is larger and for arbitrarily large countries the marginal increase is equal to $g(s)$ since the effect on the marginal payoff of government becomes negligible.

The utility of individual $i$ thus is

$$
U_{i}=g\left(s_{i}\right)-a g\left(s_{i}\right) d(i)+y-t\left(s_{i}\right)
$$

In these type of models, individuals who are close to each other in terms of preferences clearly prefer to from a country together. When there is no relationship between geographical location and preferences, also countries which are not connected could emerge. Assuming that geographical and preference dimension coincide prevents the creation of disconnected countries. Therefore I do not analyze geographic mobility, which would break the link between geographical locations and preferences. ${ }^{4}$

\footnotetext{
${ }^{4}$ Like Alesina and Spolaore (1997) one can fix the payoff and the costs of public good provision. Apart from the Inada conditions in $(A 1)$ this a special case of the model presented above. Doing so in this model obtains similar conclusions as Alesina and Spolaore. The model of Alesina and Spolaore is thus a special case of this framework. A rigorous proof of this is available upon request.
} 
I now discuss two examples of public goods or types of government along with the model. For the first example, consider monetary policy. An individual benefits from living in a larger jurisdiction with a single currency since its money is used more widely. The distance costs, however, are that the monetary policy in a large jurisdiction probably differs from the one preferred by this individual while the costs of monetary policy are decreasing in the size of the jurisdiction, reflecting economies of scale. For the second example, consider a machinery of government. Larger jurisdictions have larger machineries, which is advantageous, but an individual also has to travel more to the point where the government is located. As long as the number of civil servants is increasing less than proportionally in country size, the per capita costs are falling in country size. In the first example, the model is interpreted in a preference dimension, while in the last example the interpretation is geographical.

In order to study the equilibrium size of countries, I define three rules governing secession and determining the equilibrium size of countries: the principles of (i) internal stability and (ii) border stability and (iii) how a border change of a country is affecting other countries. What I call the principle of internal stability implies that individuals within a country make decision on country size in referenda with pairwise comparisons of country sizes. In a country, referenda can be held on increasing or on decreasing its size. The second principle I call border stability. If an individual on the border of a country wants to abandon a country and join a neighboring one, individuals of the former country cannot prevent it. It implies that when an equilibrium is subject to a minor border change, the system returns to the position with the same equilibrium size of countries. The third principle is that when a country size is changed, all countries at the side of the border change move to make up for the change.

Finally, in the general model country size is determined first and then the individuals vote on the type of public goods provided in each country.

\section{Analysis of the general model}

In this section the socially optimal outcome is studied first. Then the internal and border stable country sizes are used to determine the equilibrium country 
size and the section concludes with a comparison of the socially optimal and the equilibrium country size.

In the social optimum the locations and sizes of countries are chosen to maximize the aggregate payoff. This is equivalent with maximizing the average payoff of an individual. More details on the derivation of the socially optimal country size are in the Appendix.

Proposition 3.1. The socially optimal size $s$ of a country is implicitly given by $\frac{1}{4} a \frac{d}{d s} s g(s)=g^{\prime}(s)-t^{\prime}(s)$.

It follows that a benevolent planner balances the marginal effect of distance costs (on the left hand side of the equality) with an individual's gain of an increase in country size (on the right hand side of the equality). The marginal gain of an increase in country size is the nett effect due to the increase in public good provision, $g^{\prime}(s)$, corrected for the decrease in the tax level, $t^{\prime}(s)$. An increase in the distance costs parameter $a$ decreases the socially optimal size of a nation.

In order to study the equilibrium size of countries, I have defined rules affecting country size. The first principle is that of internal stability. Details on the derivation of the internal stable country size are in the Appendix. The internal stable size $s$ of a country is implicitly given by $\frac{1}{2} a g(s)=g^{\prime}(s)-t^{\prime}(s)$. It follows that individuals compare the increase in distance costs with an individual's gain of an increase in country size. An increase in the distance costs parameter $a$ thus decreases the internal stable size of a nation. When distance costs become more important, individuals will get stronger preferences for living in a small country and thus refusing the enlargement of their country.

The second principle is that of border stability. Details of the computation of the following are in the Appendix. The border stable size $s$ of a country is implicitly given by $\frac{1}{2} a \frac{d}{d s} s g(s)=g^{\prime}(s)-t^{\prime}(s)$. Individuals thus compare the marginal effect of distance costs with an individual's gain of an increase in country size. An increase in the distance costs parameter $a$ decreases the border stable size of a nation. When distance costs become more important, individuals will get stronger preferences for living in a small country and thus leaving a big one for a small one.

In the following Proposition I give the equilibrium size of countries under majority voting. Countries of this size are internal as well as border stable. The result immediately follows from the results stated above. 
Proposition 3.2. The equilibrium size s of countries under majority voting is given by the minimum value satisfying $\frac{1}{2} a g(s)=g^{\prime}(s)-t^{\prime}(s)$ and $\frac{1}{2} a \frac{d}{d s} s g(s)=$ $g^{\prime}(s)-t^{\prime}(s)$.

By coincidence it might be the case that the internal and border stable sizes are equal, ${ }^{5}$ but first consider what happens when the internal stable size is smaller and than what happens when the internal stable size is larger than the border stable size. In the first case, the individuals in a certain country do not prefer the enlargement of their country with individuals which are willing to join the country. This might be a cause of migration. In the second case, individuals in a certain country want to secede, while the other individuals in the country prefer the actual country size. This can be interpreted as a cause of the origination of -possibly violent- secessionist movements.

Now compare the social optimum with the outcome under majority voting. For both cases country sizes are implicitly given above.

Corollary 3.1. Since $\frac{1}{4} a \frac{d}{d s} s g(s)<\frac{1}{2} a \frac{d}{d s} s g(s)$, majority voting leads to excessive incentives for separation.

From the inequalities implicitly specifying the internal and border stable country sizes the terms on the right hand side, $g^{\prime}(s)-t^{\prime}(s)$, show that the potential marginal benefits from a change in country size are equal for all individuals. The individuals, however, do not internalize the losses or gains secession brings forth for other individuals. Individuals on the boundary look at the marginal increase in their payoff $\left(\frac{1}{2} a \frac{d}{d s} s g(s)\right)$ when they join the neighboring country. Individuals in a country focus at the additional transportation costs $\left(\frac{1}{2} a g(s)\right)$ an increase in country will imply. The individual's distance costs are larger than the aggregate costs $\left(\frac{1}{2} a \frac{d}{d s} s g(s)\right)$ of an increase in country size.

\footnotetext{
${ }^{5}$ When fixed costs/fixed benefits assumptions for the public good are used, the internal and border stable country sizes are equal.
} 


\subsection{Rules for changing country size}

Bordignon and Brusco (2001) ask whether the constitution of a federation should allow for peaceful secession. In case the federation breaks down they argue that constitutionally defined secession rules are optimal ex post. On the other hand the success of a federation also depends on the perception of its future duration. Not having constitutional secession rules makes secession more difficult and thus provides an economic advantage. As Bordignon and Brusco noticed, in most countries individuals do not have the right to secede or the right to secede is severely constrained. It is therefore relevant to examine the rules for changing country size in more detail. In this section, I consecutively look at what I will call (i) an autocratic world; (ii) a harmonious world and (iii) an individualistic world. In an autocratic world individuals on located on the border do not have the right to secede, in a harmonious world secession can only take place under unanimity and in an individualistic world only individuals located on the border take personal decisions on secessions.

Since the excessive incentives of separation can result from individuals on the border not taking into account the externalities secession has on the other individuals, the excessive incentives for separation may be mitigated by limiting the possibility of individuals to secede. In an autocratic world individuals located at the border indeed do not have the freedom granted to them by the border stability rule. Examples of autocracy are Russia in Chechnya and China in Tibet. Another reason to limit the freedom of individuals on the border is when a majority of the citizens in a country value their country's political and military might. Since a country's standing in the world also depends its size, a majority of the country's citizens may specify a constitution which rules out secession. This can be modelled by skipping the border stability rule, but keeping the internal stability rule in combination with the assumption that when a bordering country is affected by a change, all countries at the side of the affected country moved to make up for the change. The equilibrium size $s$ of countries in an autocratic world is given by $\frac{1}{2} a g(s)=g^{\prime}(s)-t^{\prime}(s)$. Since $\frac{1}{2} a g(s)$ can be smaller and larger than $\frac{1}{2} a \frac{d}{d s} s g(s)$, we see that we cannot say a priori that in an autocratic world the equilibrium size of countries is smaller than the socially optimal size. This result puts the finding by Alesina and Spolaore (1997) that democratization leads to 
smaller country size in a broader perspective. Instead of diminishing the possibilities of exploiting more individuals in larger countries, democratization would now imply that individuals get more rights, among other rights the right to secede. This result also implies that due to the absence of constitutional secession rules, countries in the real world are not necessary smaller than socially optimal.

The internal stability rule requires just a majority for a border change. In a harmonious world it can be the case that unanimity within a group is required for a secession of the group or an annexation by the group. An example is the European Union, where there are no constitutional rules specifying how a nation can leave the union. When a country plans to leave the Union, approval by all the others would be necessary. ${ }^{6}$ In a harmonious world the rule for changing country size would then require that individuals within a country make decision with unanimity on country size in referenda with pairwise comparisons of country sizes. I use this rule together with the assumption that when a bordering country is affected by a change, all countries at the side of the affected country moved to make up for the change. When the voter at $s / 2$ prefers an increase in country size all the individuals have the same preference. The voter at $s / 2$, however, is always against a decrease in country size since this decrease implies a smaller government and higher transportation costs. The minimum size of a country in a harmonious world therefore is the internal stable size in the general model. Bordignon and Brusco (2001) argue that the absence of the possibility to secede in a peaceful and constitutional way, like we have in a harmonious world, can have serious consequences. When a nation would decide to leave the European Monetary Union or the European Union, it will result in a severe disruption of economic and political relations in Europe. This makes clear that there is disadvantage of the secession rules used in this case. My result also implies that the European Monetary Union or the European Union may be larger than socially optimal.

In an individualistic world or in certain anarchistic situations, individuals do not collectively take decisions on increasing or decreasing country size. Since the internal stability rule requires coordinated decision making with a group of

\footnotetext{
${ }^{6}$ The proposals for a constitution of the Union made by Giscard d'Estaing do contain rules specifying how a country can leave the Union.
} 
individuals, in an individualistic world the internal stability rule does therefore not hold. The border stability rule, however, is applicable on an individual basis. Thus in an individualistic world only individuals located on the border take personal decisions on secessions, this in contradistinction to an autocratic world. The equilibrium size of countries in an individualistic world might therefore be higher than in the general model, depending on whether the internal stability or the border stability rule was binding for the equilibrium size of countries. This leads to the somewhat surprising result that more individualization might actually lead to a larger country size.

\section{Taxation}

Now suppose that the maximum utility of the public good in country $i$ only depends on the total tax revenue in the country. We can denote this maximum payoff by $g\left(s_{i} t\left(s_{i}\right)\right)$. The utility of an individual $i$ then becomes the following.

$$
U_{i}=g\left(s_{i} t\left(s_{i}\right)\right)-a g\left(s_{i} t\left(s_{i}\right)\right) d(i)+y-t\left(s_{i}\right)
$$

An additional assumption I need in this section is that $s t(s)$ is increasing in $s$. This implies that total public spending is increasing in country size, which is consistent with the empirical findings of Alesina and Wacziarg (1998).

To determine the social optimum we have to choose the location and size of a country to maximize the aggregate payoff. This is equivalent with maximizing the average payoff of an individual. The outcome of the maximization is that the socially optimal size $s$ of a country is implicitly given by $\frac{1}{4} a \frac{d}{d s} s g(s t(s))=$ $\frac{d}{d s} g(s t(s))-\frac{d}{d s} t(s)$ and the internal stable size of a country is implicitly given by $\frac{1}{2} a g(s t(s))=\frac{d}{d s} g(s t(s))-\frac{d}{d s} t(s)$. The border stable size $s$ of a country is

implicitly given by $\frac{1}{2} a \frac{d}{d s} s g(s t(s))=\frac{d}{d s} g(s t(s))-\frac{d}{d s} t(s)$. These results can be derived with straightforward adjustments in the derivations of the corresponding results in Section 3. In the following Proposition I give the equilibrium size of countries under majority voting and the socially optimal country size. Countries of this size are internal as well as border stable. The Proposition immediately follows from the results stated above. 
Proposition 4.1. The equilibrium size $s$ of countries under majority voting is given by the minimum value satisfying $\frac{1}{2} a g(s t(s))=\frac{d}{d s} g(s t(s))-\frac{d}{d s} t(s)$ and $\frac{1}{2} a \frac{d}{d s} s g(s t(s))=\frac{d}{d s} g(s t(s))-\frac{d}{d s} t(s)$. The socially optimal size $s$ of a country is implicitly given by $\frac{1}{4} a \frac{d}{d s} s g(s t(s))=\frac{d}{d s} g(s t(s))-\frac{d}{d s} t(s)$.

Since $\frac{1}{4} a \frac{d}{d s} s g(s t(s))<\frac{1}{2} a \frac{d}{d s} s g(s t(s))$, we see that just as in the general case, majority voting leads to excessive incentives for separation. The above results are parallel to the results in Section 3, see this Section for more discussion.

\subsection{Increase in public spending}

In the last 50 years the absolute level as well as the relative share of public spending has increased remarkably. In this subsection I will investigate the influence of this increase on country size. The main result is that an exogenous increase in public spending decreases the equilibrium as well as the socially optimal country size.

Now assume that lump sum tax level an individual in country $i$ has to pay is $\hat{\beta}+t\left(s_{i}\right)$, where $\hat{\beta}>0$ denotes the increase in public spending. It is easy to verify that this new tax level does not affect the assumptions on $g($.$) and t($. specified in Sections 2 and 4.

From Proposition 3.1 we know that the socially optimal country size $s$ of a country is implicitly given by

$$
\frac{1}{4} a \frac{\partial}{\partial s} s g(s(\hat{\beta}+t(s)))=\frac{\partial}{\partial s} g(s(\hat{\beta}+t(s)))-\frac{\partial}{\partial s}(\hat{\beta}+t(s))
$$

Since $\frac{\partial}{\partial s} s g(s)$ is positive and increasing in $s$, it follows that an increase in $\hat{\beta}$ will increase $\frac{1}{4} a \frac{\partial}{\partial s} s g(s(\hat{\beta}+t(s)))$. Moreover, an increase of $\hat{\beta}$ will decrease $\frac{\partial}{\partial s} g(s(\hat{\beta}+t(s)))-\frac{\partial}{\partial s}(\hat{\beta}+t(s))$. Since an increase in $s$ has similar effects, it follows that an increase $\hat{\beta}$ will decrease the socially optimal country size $s$.

From Proposition 4.1 it follows that the equilibrium size of $s$ of countries under majority voting is given by the minimum value satisfying

$$
\begin{gathered}
\frac{1}{2} a g(s(\hat{\beta}+t(s)))=\frac{\partial}{\partial s} g(s(\hat{\beta}+t(s)))-\frac{\partial}{\partial s}(\hat{\beta}+t(s)) \\
\quad \text { and } \\
\frac{1}{2} a \frac{\partial}{\partial s} s g(s(\hat{\beta}+t(s)))=\frac{\partial}{\partial s} g(s(\hat{\beta}+t(s)))-\frac{\partial}{\partial s}(\hat{\beta}+t(s))
\end{gathered}
$$


An increase in $\hat{\beta}$ will decrease the equilibrium country size $s$ since changes in $\hat{\beta}$ and in $s$ have similar effects on $\frac{1}{2} a g(s(\hat{\beta}+t(s))), \frac{1}{2} a \frac{\partial}{\partial s} s g(s(\hat{\beta}+t(s)))$ and $\frac{\partial}{\partial s} g(s(\hat{\beta}+t(s)))-\frac{\partial}{\partial s}(\hat{\beta}+t(s))$.

From the above it follows that both the socially optimal and the equilibrium country size decreases due to an increase in public spending. I formalize this in the following Proposition.

Proposition 4.2. Higher levels of public spending negatively effects the equilibrium as well as the socially optimal country size.

This results from two effects. In the first place, an increase in public spending leads to an increase in the importance of the distance costs. This is represented by $\frac{1}{2} a g(s(\hat{\beta}+t(s)))$, by $\frac{1}{4} a \frac{\partial}{\partial s} s g(s(\hat{\beta}+t(s)))$ and by $\frac{1}{2} a \frac{\partial}{\partial s} s g(s(\hat{\beta}+t(s)))$. More public spending thus induces greater incentives to decrease the distance to the public good. In the second place, an increase in public spending decreases the marginal increase in payoff of increasing country size. This is represented by $\frac{\partial}{\partial s} g(s(\hat{\beta}+t(s)))-\frac{\partial}{\partial s}(\hat{\beta}+t(s))$. Higher public spending levels decreases the marginal increase of the maximum payoff of the public good $\frac{\partial}{\partial s} g(s(\hat{\beta}+t(s)))$, not altering the marginal change in the tax level $\frac{\partial}{\partial s}(\hat{\beta}+t(s))$.

\subsection{Parliamentary and presidential-congressional democ- racies}

In this section I study how a political regime influences the public good provision and how this affects the equilibrium size of nations. The first political regime is the parliamentary democracy, where there is a single vote for both the executive and legislative power. In a presidential-congressional democracy, the second regime, there are two separate votes, one for the executive and one for the legislative power. The decision making in a parliamentary democracy is modelled as the election of a so-called citizen candidate. In referenda the individuals in a country can choose between two candidates and the candidate who will finally prevail will determine both the amount and the type of the public good provided by the country. The decision making in a presidential-congressional democracy is modelled with two referenda. In the first referendum the type of the public good is determined while in the second referendum the individuals decide on the level of public goods provision. 
In the model of a parliamentary democracy individuals in each country thus elect a representative who will determine the amount of public spending as well as the location of the government. The elected candidate locates the government at his ideal point and chooses the level of public spending (an thus the tax level) to maximize his own payoff. Hence, each candidate will set the same level of public spending if elected. Candidates thus differ only in where they will locate the government. Clearly, the individual in the middle of the country is the only candidate which can not be beaten in an election with two candidates. The elected candidate thus maximizes the following with respect to the tax level $t(s)$.

$$
g(s t(s))+y-t(s)
$$

The elected candidate therefore equalizes his marginal benefit of public spending with his marginal costs of public spending, that is $g^{\prime}(s t(s))=1 / s$.

The median voter theorem implies that in the model of presidential-congressional democracy individuals decide in the referendum on the type of public goods to locate the public goods in the middle of their country. It then follows that the median voters for the level of public good provision are located at $1 / 4$ and $3 / 4$ of a country. Half the individuals (the individuals between $1 / 4$ and $3 / 4$ ) have smaller distance costs and therefore want to provide more public goods, while half the individuals have larger distance costs and therefore want to provide less public goods. For a given country size $s$ the two median voters choose a tax level $t(s)$ to maximize the following.

$$
g(s t(s))-\frac{1}{4} \operatorname{asg}(s t(s))+y-t(s)
$$

The two median voters therefore equalize their marginal benefit of public spending with their marginal costs of public spending, that is $g^{\prime}(s t(s)) /\left(1-\frac{1}{4} a s\right)=1 / s$.

For a comparison of public good provision under both regimes first note that in both cases the public good will be located in the middle of the country. To compare the levels of public good provision, it is convenient to rewrite the condition in the parliamentary democracy as $g^{\prime}(s t(s))=1 /\left(s-\frac{1}{4} a s^{2}\right)$. Since $\left(1-\frac{1}{4} a s\right) / s<1 / s$ and since $g^{\prime}($.$) is a decreasing function in its argument it follows that more public$ goods will be provided in a parliamentary democracy then in a presidentialcongressional democracy. I can now state the main result of this section. 
Proposition 4.3. The equilibrium size of countries with parliamentary regimes is smaller than the equilibrium size of countries with presidential-congressional regimes.

The result of Proposition 4.3 follows from the combination of the results presented in this section with the result stated in Proposition 4.2.

\section{Concluding remarks}

This paper has studied the equilibrium country size: in small countries individuals have a greater influence over the nature of political decision making while in larger countries individuals benefit from lower tax levels and higher public good levels. The extension of the Alesina and Spolaore (1997) framework, making amounts and payoffs of public spending depending on country size, allows to study the relation between public good provision and country size. In the general model, under majority voting the equilibrium size of countries is too small from a social point of view. This need not be the case, however, if one uses other rules for secession. I also argued that an exogenous increase in public spending decreases the equilibrium size of countries, and that the equilibrium size of countries with a presidential-congressional democracy is larger than of countries with a parliamentary democracy.

Two possible directions for further research are the introduction of congestion effects and nonlinear transportation costs in the model. In addition to the increase in heterogeneity of the population, other counterbalancing effects of increasing the size of jurisdictions mentioned by Alesina and Spolaore are congestion and coordination problems. These effects can be studied in the model by specifying a payoff function $g(s)$ which is initially increasing but then decreasing in country size. The examination of nonlinear transportation costs in the model can be done by using any arbitrary function $d(i)$ which is increasing in distance of the individual to its government, instead of using a linear function. Broader directions for further research are the introduction of decentralized public good provision, competition of countries with for example defense spending or the distributive role of governments.

My research also offers hypotheses for further empirical work. A first conjec-

ture is that the increase in public spending has had a negative impact on country 
size. The level of public spending indeed has increased on a large scale and simultaneously the number of countries increased -and thus the size decreased- in the last decennia. However, one has to adjust for external factors like decolonization. A second conjecture is that countries with a presidential-congressional system are on the average larger than countries with a parliamentary system.

\section{Appendix}

Country size and the social optimum

Since the costs of preference distance are linear, maximizing the average payoff of an individual is equivalent with maximizing the payoff of the individuals located at $1 / 4$ and $3 / 4$ of a country. The payoff of an individual located at $s / 4$ or $3 s / 4$ in a country of size $s$ is

$$
g(s)-\frac{1}{4} \operatorname{asg}(s)+y-t(s)
$$

Rewriting the first-order condition for maximization with respect to $s$ gives

$$
\frac{1}{4} a\left(g(s)+s g^{\prime}(s)\right)=g^{\prime}(s)-t^{\prime}(s)
$$

Note that $g(s)+s g^{\prime}(s)=\frac{d}{d s} s g(s)$. Since the marginal increase in the aggregate payoff of all citizens of a country is increasing in country size, $\frac{1}{4} a \frac{d}{d s} s g(s)$ is increasing in $s$ and since the marginal gains of increasing country size are diminishing, $g^{\prime}(s)-t^{\prime}(s)$ is decreasing in $s$. For $s$ arbitrary large, it is equal to zero. This ensures that the socially optimal country size is unique.

\section{Country size and internal stability}

Without loss of generality assume that in the first place the individual considering to join the country is located adjacent to and at the right hand side of the country and that in the second place the country under consideration is located between $(0, s)$. An immediate application of the median voter theorem implies that the government is located in the middle of each country, given country borders.

First I will consider the preference of an individual in the middle of the country, that is, the individual located at $s / 2$. The individual located at $s / 2$ will 
prefer a country of size $s^{\prime}$ over a country of size $s$ when his payoff in the former case is larger. That is, when

$$
g\left(s^{\prime}\right)-a d\left(s / 2, s^{\prime}\right) g\left(s^{\prime}\right)+y-t\left(s^{\prime}\right)>g(s)-a d(s / 2, s) g(s)+y-t(s)
$$

Since the public goods will be located in the middle of each country and for $s^{\prime}>$ $s, d\left(s / 2, s^{\prime}\right)=1 / 2\left(s^{\prime}-s\right)$ and $d(s / 2, s)=0$. We can thus rewrite inequality (9) as follows.

$$
\frac{1}{2} a g\left(s^{\prime}\right)<\frac{g\left(s^{\prime}\right)-g(s)}{s^{\prime}-s}-\frac{t\left(s^{\prime}\right)-t(s)}{s^{\prime}-s}
$$

Taking the limit of $s^{\prime}$ approaching $s$ gives:

$$
\frac{1}{2} a g(s)<g^{\prime}(s)-t^{\prime}(s)
$$

For $s^{\prime}<s$ the inequality signs of (10) and (11) will reverse.

Since the marginal gains of increasing country size are diminishing, we have that $g^{\prime}(s)-t^{\prime}(s)$ is decreasing in $s$ and obviously, $\frac{1}{2} a g(s)$ is increasing in $s$. Therefore, $\frac{1}{2} a g(s)=g^{\prime}(s)-t^{\prime}(s)$ has a unique solution.

Finally, it is straightforward to show that all the individuals between 0 and $s / 2$ will prefer $s$ over $s^{\prime}$ when $s^{\prime}>s$ and that the individuals between $s / 2$ and $s$ will prefer $s$ over $s^{\prime}$ when $s^{\prime}<s$.

\section{Country size and border stability}

A person at the boundary of a country might join another country, but the individual will not do this if his payoff decreases when he moves to the neighboring country. That is, an individual will not move from a country of size $s$ to a country of size $s^{\prime}$ when the following inequality holds.

$$
g(s)-\frac{1}{2} a s g(s)-t(s)>g\left(s^{\prime}\right)-\frac{1}{2} a s^{\prime} g\left(s^{\prime}\right)-t\left(s^{\prime}\right)
$$

This can be rewritten as follows:

$$
\frac{1}{2} a s^{\prime} g\left(s^{\prime}\right)-\frac{1}{2} a s g(s)>g\left(s^{\prime}\right)-g(s)-\left(t\left(s^{\prime}\right)-t(s)\right)
$$

When $s^{\prime}>s$ this is equivalent with the following.

$$
\frac{\frac{1}{2} a s^{\prime} g\left(s^{\prime}\right)-\frac{1}{2} a s g(s)}{s^{\prime}-s}>\frac{g\left(s^{\prime}\right)-g(s)}{s^{\prime}-s}-\frac{t\left(s^{\prime}\right)-t(s)}{s^{\prime}-s}
$$


Taking the limit of $s^{\prime}$ approaching $s$ gives:

$$
\frac{1}{2} a \frac{d}{d s} s g(s)>g^{\prime}(s)-t^{\prime}(s)
$$

For $s^{\prime}<s$ the inequality signs of (14) and (15) will reverse.

Since the marginal gains of increasing country size are diminishing, we have that $g^{\prime}(s)-t^{\prime}(s)$ is decreasing in $s$ and by assumption $\frac{1}{2} a \frac{d}{d s} s g(s)$ is increasing in $s$. Therefore, $\frac{1}{2} a \frac{d}{d s} s g(s)=g^{\prime}(s)-t^{\prime}(s)$ has a unique solution.

\section{References}

[1] Alesina, A. and E. Spolaore (1997), On the number and size of nations, Quarterly Journal of Economics, 112, 1027-1056.

[2] Alesina, A. and R. Wacziarg (1998), Openness, country size and government, Journal of Public Economics, 69, 305-321.

[3] Besley, T. and S. Coate (2003), Centralized versus decentralized provision of local public goods: A political economy approach, Jornal of Public Economics, 87, 2611-2637.

[4] Bolton, R. and G. Roland (1987), The breakup of nations: A politival economy analysis, Quarterly Journal of Economics, 112, 1057-1090.

[5] Bolton, R., G. Roland and E. Spolaore (1996), Economic theories of the break-up and integration of nations, European Economic Review, 40, 697705.

[6] Bordignon, M. and S. Brusco (2001), Optimal seccesion rules, European Economic Review, 45, 1811-1834.

[7] Buchanan, J.M. and R.L. Faith (1987), Secession and the limits of taxation: Toward a theory of internal exit, American Economic Review, 77, 1023-1031.

[8] Casella, A. (1992), On markets and clubs: Economic and political integration of regions with unequal productivity, American Economic Review, 8, 115-121. 
[9] Casella, A. and J. Feinstein (2002), Public goods in trade: On the formation of markets and jurisdictions, International Economic Review, 43, 437-462.

[10] Ellingsen, T. (1998), Externalities vs internalities: A model of political integration, Journal of Public Economics, 68, 251-268.

[11] Etro, F. (2003), Globalization and political geography, CESifo Working Paper No. 986.

[12] Feinstein, J. (1992), Public good provision and political stability in Europe, American Economic Review, 82, 323-329.

[13] Fidrmuc, J. (1999), Stochastic shocks and incentives for (dis)integration, CEPR Discussion Paper No. 2104.

[14] Goyal, S. and K. Staal (2003), The political economy of regionalism, European Economic Review, forthcoming.

[15] Hotelling, H. (1929), Stability in Competition, Economic Journal, 39, 4157.

[16] Le Breton, M. and S. Weber (2001), The art of making everybody happy: How to prevent a secession, IMF Working Paper No. 01/176.

[17] Lockwood, B. (2002), Distributive politics and the costs of centralization, Review of Economic Studies, 69, 313-337.

[18] Persson, T., G. Roland and G. Tabellini (2000), Comparative politics and public finance, Journal of Political Economy, 6, 1121-1161.

[19] Persson, T. and G. Tabellini (1996), Federal fiscal constitutions: Risk sharing and moral hazard, Econometrica, 64, 623-646.

[20] Persson, T. and G. Tabellini (1996), Federal fiscal constitutions: Risk sharing and redistribution, Journal of Political Economy, 104, 979-1009.

[21] Rodrik, D. (1998), Why do more open economies have bigger governments?, Journal of Political Economy, 5, 997-1032. 
[22] Tanzi, V. and L. Schuknecht, Public spending in the 20th century, Cambridge: Cambridge University Press, 2000.

[23] Wei, S.J. (1991a), To divide or to unite: A theory of secessions, mimeo, University of California at Berkeley.

[24] Wei, S.J. (1991a), Federation or commonwealth: An alternative to secessions, mimeo, University of California at Berkeley. 